\section{Images from Skylab}

SKYLAB Explores the Earth. Prepared by NASA Lyndon B. Johnson Space Centre. Pp. 517. (NASA.) $£ 29.50$.

SKYLAB represents to space image users and researchers alike, a collection of over 35.000 frames of the highest quality colour, stereoscopic, photographic images yet acquired from a space platform. The actual magazines of film were returned to Earth for processing and development, resulting in the greatest degree of spatial resolution $\left(55^{\prime}-100^{\prime}\right)$ yet obtained on images acquired in space. All other imaging satellite sensing systems rely on the transmission of data by electronic means from the space vehicle to Earth, where images are regenerated with an accompanying degradation of resolution. When I saw the title of this publication from NASA, I had therefore expected a comprehensive selection of high resolution, stereoscopic, photographic images depicting Earth terrain, and oceanic and meteorological patterns and conditions. This expectation was unfulfilled, for in effect, this particular publication deals only with a sampling of some 2,000 frames of hand-held colour imagery (35 and 70mm).

So much for what this publication is not! What it is then is a series of some 17 separate research studies by US Government researchers, university researchers, and private contractors, dealing with projects involved with the physical, biological, cultural, and meteorological aspects of the Earth's environment. Four chapters deal with geological features (tectonics, volcanism, impact structures and physiography; two with various aspects of desertification processes; four with meteorological phenomena; three with oceanography including one on sea ice distribution patterns; and one chapter each with snow distribution, cultural patterns, vegetation patterns, and atmospheric poluution. All this is followed by an overall summary, three appendices, a glossary, a section on weather symbolisation, and a photographic index.

The individual subjects and their treatment with respect to the use of Skylab images consist primarily of enlarged colour images with annotations either on the image itself or presented as a line drawing on the facing page. The volume is profusely illustrated in this manner with most of the images being reproduced in colour on high quality paper. It is unfortunate that many of the images and facing-page line drawings are not of the same scale or do not always cover the same area, making it difficult to transpose the annotations, by eye, across the page to the image.

Many of the authors of the respective chapters point out the value of being able to view these Skylab images stereoscopically, yet only four stereo pairs are presented in the book. Perhaps it is just as well in that each model is incorrectly spaced (3.4" apart versus a normal 2.4") for threedimensional viewing by the naked eye. Also in the screen printed reproduction of these photographic images, the attempt to use a stereoscope having any degree of magnification at all, only results in a breakdown of the scene into dots or cells of colour. A photographic process of reproduction and publication would have had to have been carried out to include stereoscopic viewing of any value.

There is one main recurring theme

\section{Europe's threatened wildlife}

The Shadow of Extinction: Europe's Threatened Wild Mammals. By Jeremy Mallinson. Pp. 224. (Macmillan: London, 1978.) $£ 5.50$.

A PRELIMINARY excursion into this book presents the reader with some puzzlement: for whom was it written and, indeed, why was it written at all? The selection of European mammals, which are dealt with in considerable detail, seems to have been somewhat arbitrary: certainly some of them, for example, the blue hare, the badger and the red squirrel, seem to be far from "the shadow of extinction".

On further perusal, some sort of rationale begins to appear. For one thing, some of the species, for example, the Pyrenean desman and the Mediterranean monk seal, are coming near to extinction and it is valuable to have their distribution, characteristics and prospects chronicled. Again, other species, which flourish still over the main part of their range, for example, the ringed seal and the red deer, have small, isolated populations which may quickly vanish and it is just these outliers that may have interesting biological characteristics, as yet unrecorded. Thirdly, details about many of these species are hard to find in the present literature, though one or two works on Palaearctic mammals are nearing publication.

As Dr Bourlière says in his Foreword, Europe is remarkable in that so few actual exterminations of mammal species have occurred within historic running through the material presented in this publication. Each study concludes that it is extremely valuable to have man and his decision-making capabilities in space utilising equipment of the highest quality to document and record his observations rather than to solely rely upon remotely controlled instrumentation. In this I would concur, especially when dealing with transitory subjects (amply depicted in this volume). However, I also believe that the best photographic system aboard Skylab was the vertically oriented S-190B Earth Terrain Camera system which was designed to achieve the optimum stereoscopic images of the Earth but which is not displayed here. The best of Skylab is yet to come.

Vernon H. Anderson

Vernon H. Anderson is President of the Photographic Interpretation Corporation, Hanover, New Hampshire.

times, but the threat lies in the decline in numbers and the fragmentation of what were widely spread, continuous populations. Here, Mr Mallinson's information is useful for pin-pointing where the dangers lie and what measures of conservation are needed.

It is when one comes to examine the documentation that one realises the weak points of this book. The bibliography is a remarkable hodge-podge, ranging from popular works like the Sunday Times series of booklets on British mammals to a few cardinal works such as van den Brink's Field Guide to the Mammals of Britain and Europe and Smit and van Wijngaarden's Threatened Mammals in Europe. The latter does not contain quite the same selection of species but it has been relied on very heavily, especially for maps and distributions. In fact, some sections, for example, the world distribution of the walrus, are extracted almost verbatim. Few journal papers are cited and, in these, page numbers are not given. Furthermore, in one instance (Godfrey, 1975), $\mathrm{Mr}$ Mallinson has thoughtfully provided a title of his own invention, which makes the reference somewhat difficult to trace.

On the whole, for a scrupulous presentation of the subject, I would recommend Smit and van Wijngaarden's report to the Council of Europe's European Committee for the Conservation of Nature and Natural Resources, though this has no pictures.

\section{H. N. Southern}

H. N. Southern recently retired as Senior Research Officer of the Animal Ecology Research Group in the Department of Zoology, University of Oxford, UK. 